\title{
The effects of apoptosis vulnerability markers on the myocardium in depression after myocardial infarction
}

Yiming Wang ${ }^{1,2+}$, Xingde Liu ${ }^{3+}$, Dongfeng Zhang ${ }^{1,4}$, Jianhui Chen ${ }^{1}$, Shuzheng Liü ${ }^{3}$ and Michael Berk $2,5,6,7^{*}$

\begin{abstract}
Background: There is an increased incidence of major depressive disorder (MDD) in individuals after myocardial infarction (MI), but the pathophysiological processes mediating this association are unclear. Our previous study demonstrated an increase in pro-apoptotic pathways in the myocardium and hippocampus in MDD, which was reversed by venlafaxine. This study aimed to attempt to confirm the effects of apoptosis vulnerability markers on the myocardium in a model of depression after myocardial infarction.

Methods: Rats were divided into four groups: sham $(N=8)$, depression ( $N=8$, chronic mild unpredictable stress and separation were used in the depression group), $\mathrm{MI}(\mathrm{N}=13)$ and post-MI depression $(\mathrm{N}=7)$. The rats in all four groups underwent the same open field and sucrose preference behavioral tests. Evan Blue staining was used to determine the area at risk of myocardial infarction in the left ventricle, and 2,3,5-triphenyl tetrazolium chloride (1.5\% TTC) dye was used to detect the size of the myocardial infarction. The expression of bax and bcl-2 protein in the myocardium was investigated by immunohistochemistry, and the mRNA expression of bax, bcl-2 and caspase-3 in the myocardium was investigated by real time RT-PCR. Apoptosis was estimated in the myocardium by measuring the $\mathrm{Bax}: \mathrm{BCl}-2$ ratio.
\end{abstract}

Results: In the depression and post-Ml depression rats, there were significantly decreased movements and total sucrose consumption, modeling behavioral deficits and an anhedonic-like state. In terms of myocardial infarction size, no difference was seen between the Ml and post-Ml depression groups. There was an up-regulated Bax:BCl-2 ratio in the depression, $\mathrm{Ml}$ and post-MI depression groups. Furthermore, in the latter group, there was a greater up-regulated Bax:Bcl-2 ratio. However, caspase-3 did not differ among the four groups.

Conclusions: These results of this animal model suggest that active pro-apoptotic pathways may be involved in the nexus between myocardial infarction and depression. This mechanism may be germane to understanding this relationship in humans.

Keywords: major depressive disorder, myocardial infarction, apoptosis, myocardium, stress, cardiac, comorbidity.

\section{Background}

Depression is a major contribution to the global disease burden, and is widely accepted as an independent risk factor in patients with coronary artery disease (CAD). Comorbidity is associated with poorer outcomes [1-5]. Myocardial infarction (MI) is the most serious clinical

\footnotetext{
* Correspondence: mikebe@barwonhealth.org.au

+ Contributed equally

${ }^{2}$ School of Medicine, Deakin University, 1 Gheringhap Street, Geelong, VIC

3220, Australia

Full list of author information is available at the end of the article
}

form of CAD [6]. There is an increased incidence of major depressive disorder (MDD) (15 to 30\%) after myocardial infarction (MI) [7]. Equally, depression is linked to a 2.0- to 2.5-fold increased risk in new cardiovascular events and increased cardiac mortality [8-10]. Patients frequently develop depressive symptoms after an acute MI, and depression is linked to an increased long-term risk of morbidity and mortality [11]; however, the pathophysiological mechanisms underpinning the relationship between MI and depression remain poorly understood.

\section{Biomed Central}


Apoptosis or programmed cell death is a process of ordered, active, non- inflammatory cell death. Bcl-2 is one member of a family of genes which can be divided into two categories according to their effects on apoptosis, one group promoting apoptosis, including Bax, Bak, Bad and Bcl-xS, a second group inhibiting cell death pathways, including Bcl-2 and Bcl-xl $[12,13]$. Of these proteins, $\mathrm{Bcl}-2$, Bax and $\mathrm{Bcl}-\mathrm{x}$ are the best characterized genes in the Bcl-2 family [14]. In the presence of stress, Bcl-2 family proteins congregate at the outer mitochondrial membrane and play a role in the regulation of apoptosis. Pro-apoptotic Bax and Bak undergo conformational changes and Bax translocates from cytosol to mitochondria via homo-oligomerization with cell stress signals [15].

The Bax/Bcl-2 ratio is a measure of a cell's vulnerability to apoptosis, a higher $\mathrm{Bax} / \mathrm{Bcl}-2$ ratio is associated with a greater vulnerability to apoptotic activation, and up-regulation of the $\mathrm{Bax} / \mathrm{Bcl}-2$ ratio suggests greater apoptotic activity [16,17]. Antidepressants, such as sertraline, can modulate depression-induced behavior and biochemical markers after myocardial infarction [18].

Caspases are a family of inactive proenzymes. Generally, there are two pathways in caspase family proteases which can be activated: one is the death receptormediated pathway that is death signal-induced; another is the mitochondrion-mediated stress-induced pathway that truncates a pro-apoptotic Bcl-2 family member [19].

Caspase- 3 is a protein that regulates apoptosis by inducing the cleavage of the key cellular proteins and alters cell integrity. The role of caspase 3 in apoptosis is to activate the stages of cellular death in a non-traumatic manner. Activation of caspase- 3 is another pathway to apoptosis.

It has been recently demonstrated that the release of pro-inflammatory cytokines in rats can induce limbic system apoptosis after an acute myocardial infarction [20-22]. Wann [23] has shown behavioral changes and an increased Bax/Bcl-2 protein ratio in limbic areas in rats with post-MI depression, suggesting a role of apoptotic events, which is similar to human findings.

Our previous study [24] demonstrated that in rats with chronic mild stress (CMS), there were significant behavioral deficits, an increase in Bax levels and a decrease in Bcl-xl levels in the myocardium and hippocampus, suggesting an increase in pro-apoptotic pathways. This was reversed by venlafaxine, which is an antidepressant of the serotonin-norepinephrine reuptake inhibitor (SNRI) class; however, in models of post-MI with depression, the role of apoptosis vulnerability markers in the myocardium is unclear, in particular associations with apoptotic pathways. We consequently hypothesized that active proapoptotic pathways in the myocardium may be involved in the nexus between cardiovascular disorders and depression.
To investigate this issue, we developed a valid model of myocardial infarction, alone and in conjunction with an anhedonic-like state in rats. This study aimed to attempt to evaluate vulnerability markers of myocardial apoptosis, specifically the Bax:Bcl-2 ratio and caspase- 3 levels in the myocardium post-MI depression, to clarify the molecular mechanisms and, as well, confirm whether the co-occurrence of myocardial infarction with MDD is associated with greater activation of apoptosis pathways.

\section{Methods}

\section{Subjects}

Male Sprague-Dawley rats $(\mathrm{N}=36$, weighing $250 \mathrm{~g} \pm 20 \mathrm{~g})$ were used for the experimental procedures. Rats were allowed to adapt to the surroundings for one week prior to the commencement of the experiment. Each rat was housed singly at room temperature $\left(22\right.$ to $\left.25^{\circ} \mathrm{C}\right)$, humidity (40 to $50 \%$ ), the light period was $12 \mathrm{~h}$ from 8 a.m., and food and water were freely available. Rats were divided into four groups: (i) sham group $(\mathrm{N}=8)$, (ii) depression group $(\mathrm{N}=8)$, (iii) MI group $(\mathrm{N}=13)$, (iv) post-MI depression group $(N=7)$. The rats in all four groups performed the same open field and sucrose preference behavioral tests. In the depression and post-MI depression rats, there were significantly decreased movements and reduced total sucrose consumption, modeling behavioral deficits and a depressive-like anhedonic state [25]. The model of post-MI depression, in which decreased movement and an anhedonic- state occurred, was observed in 7 out of 20 myocardial infarction rats in our experiment. Animals were managed in accordance with the American Psychological Association (APA) ethical standards in the treatment of rats and National Institute of Health and Guide for the Care and Use of Laboratory Animals (NIH Publications No. 80-23) revised in 1996, and the study was approved by the ethics Committee on the Guidelines for Animal Experiment at Guiyang Medical University. Efforts were made to minimize the number of animals used and their suffering.

\section{Myocardial infarction model (MI group)}

In this study, we used the myocardial infarction model of ischemia described by Wu et al., which is a validated animal model of myocardial infarction [26]. Surgeries were performed in the morning. Twenty- two rats were anesthetized by $10 \%$ chloral hydrate $(0.3 \mathrm{ml} / 100 \mathrm{~g})$, intubated, and maintained on a ventilator (R: 60 times/minute). A thoracic incision of about $2.0 \mathrm{~cm}$ was made, and the base of the heart was exposed by retractors in the central region of the rib cage. The myocardial infarction model was induced by ligating the left anterior descending coronary artery $2 \mathrm{~mm}$ from the tip of the left auricle by polypropylene suture for 40 minutes. Rats were monitored by ECG (electrocardiogram) before and after coronary artery ligation. Ischemia 
was confirmed by ST-T segment elevation in ECG recordings performed on the rats (Figure 1) [27], and after the myocardial surface became blanched, the animal was returned to its home cage after the ligation was removed and the thorax sutured for 14 days. In the sham group, eight rats were operated on using the same protocol, except the coronary artery was not ligated. After the surgery, all rats were administered an analgesic $(2 \mathrm{mg} / \mathrm{kg}$ butorphanol tartrate, s.c. every $8 \mathrm{~h}$ during the $24 \mathrm{~h}$ after surgery) and an antibiotic (10,000 IU penicillin G, i.m.). The rats did not show any signs of cardiac failure nor arrhythmias during the myocardial infarction procedure. The percentage of rats surviving the MI induction procedure was $90 \%$.

\section{Chronic mild stress model (depression)}

In this study, the chronic mild stress model was used as a validated animal model of depression [28]. Chronic mild unpredictable stress and separation were used in the depression group for 21 days. Eight rats were given the following stressors [25,29], consisting each week of repeated periods of confinement to a small $(38 \times 20 \times 16 \mathrm{~cm})$ cage, restraint $(1 \mathrm{~h})$, water deprivation $(24 \mathrm{~h})$, food deprivation $(24 \mathrm{~h})$, isolation $(24 \mathrm{~h})$, flashing light $(3 \mathrm{~h})$, forced cold water swimming (10 minutes) and were group-housed in a soiled cage overnight. Individual stressors and length of time used each day are listed in Table 1. Stressors were used daily in a random and unpredictable order for 21 days.

\section{Open field test and sucrose consumption test}

The behavior and anhedonic-like state of all rats were detected by the open field test [30] and sucrose consumption test [31]. The behavioral response to a new environment and activating behavior of rats was detected by the open field test [32], which has been used as an indicator of emotional state. This includes assessment of horizontal movements (the total number of crossing squares) and vertical movements (grooming and rearing) during a five-minute period. The former can be used as a proxy of emotional activity; the latter is regarded as a measure of exploratory activity to novel environments [33]. A special white square $(80 \times 80 \times 40$ $\mathrm{cm}$ ), which has 25 sectors with black stripes on the ground, was used. Animals were separately put in the same central sector, and their activity was recorded during a five-minute period by an installed video camera. Observers analyzed the results of videotapes. Rats in both the depression and post-MI depression groups showed significantly lower scores of both horizontal and vertical movement compared with the sham and MI groups (Figure 2A), suggesting similarly decreased behavioral indices in the post-MI depression and depression groups.

Sucrose consumption is a rat model of an anhedonialike state [34]. Every cage was offered a bottle of water and a bottle of $1 \%$ sucrose water. Total sucrose consumption was measured after 60 minutes. The test was begun $23 \mathrm{~h}$ after water and food deprivation, and the experiment was begun, and on day 15 after surgery [23] and the day after the end of the chronic mild unpredictable stress procedure [28]. Before the experiment, there were similar levels of sucrose water consumption between the four groups; however, after the experiment, the total consumptions of sucrose was significantly lower in the depression and postMI depression groups compared to the sham and MI
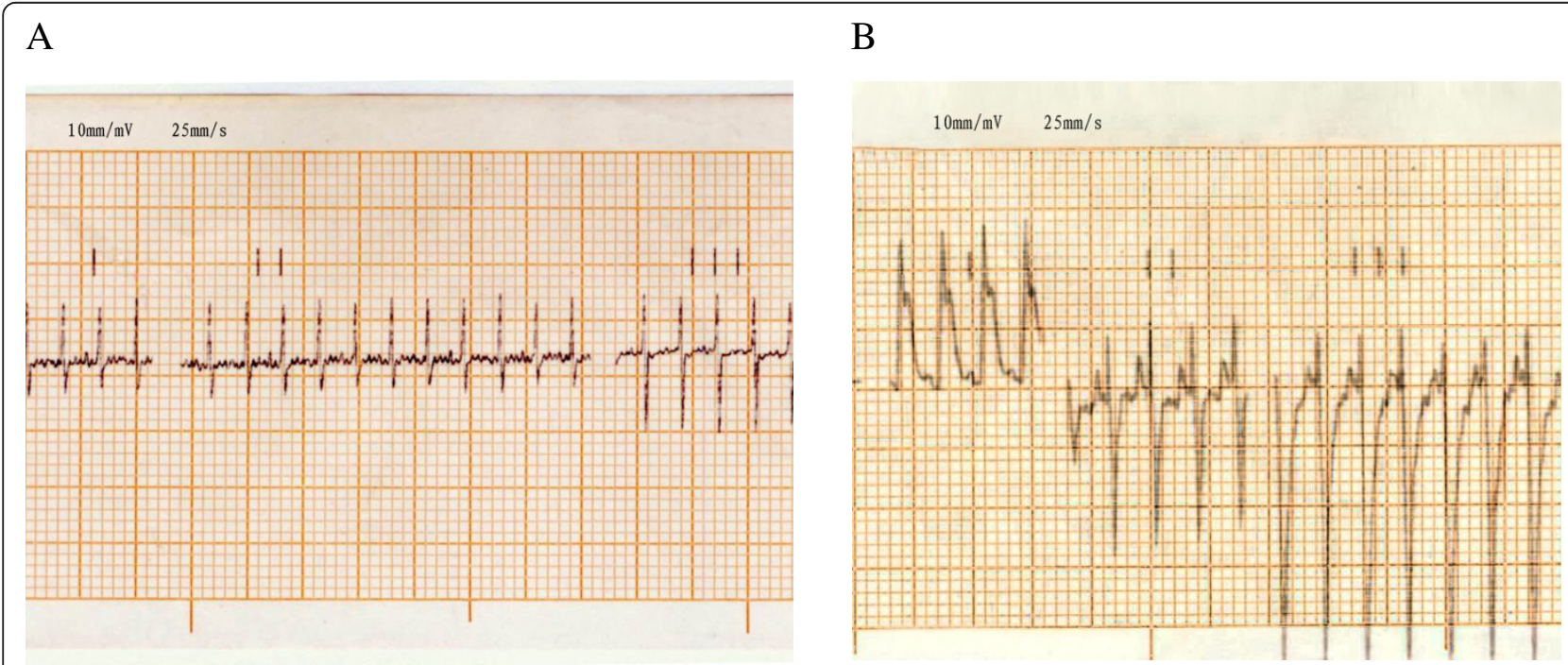

Figure 1 The electrocardiogram of the rats. A: Electrocardiogram in the normal rat. B: ST-segment elevation in leads I in myocardial ischemia rat. 
Table 1 Schedule of chronic mild stress

\begin{tabular}{|c|c|c|c|c|c|c|c|}
\hline & Monday & Tuesday & Wednesday & Thursday & Friday & Saturday & Sunday \\
\hline $\begin{array}{l}\text { Stressor } \\
\text { used }\end{array}$ & Restraint & $\begin{array}{l}\text { Water } \\
\text { deprivation }\end{array}$ & $\begin{array}{l}\text { Food } \\
\text { deprivation }\end{array}$ & Isolation & $\begin{array}{l}\text { Flashing } \\
\text { light }\end{array}$ & $\begin{array}{l}\text { Forced cold water } \\
\text { swimming }\end{array}$ & $\begin{array}{l}\text { Group-housed in soiled } \\
\text { cage }\end{array}$ \\
\hline Duration & $1 \mathrm{~h}$ & $24 \mathrm{~h}$ & $24 \mathrm{~h}$ & $24 \mathrm{~h}$ & $3 \mathrm{~h}$ & 10 minutes & overnight \\
\hline
\end{tabular}

groups (Figure 2B), suggesting the post-MI depression group was similar to the depression group in terms of developing an anhedonic-like state.

\section{Myocardial infarct size}

The rats were sacrificed by decapitation $24 \mathrm{~h}$ after completion of the behavioral tests, prior to which horizontal movements, vertical movements and sucrose consumption tests were recorded according to the experimental protocol. The heart was removed, and the aorta was cannulated and washed with saline, the left anterior descending coronary artery was ligated again at the same site, and the aorta was infused with $2 \mathrm{ml}$ of $0.5 \%$ Evan's blue to determine the extent of the non-colored ischemic risk area, then the myocardium was bisected into two parts from the apex to the base along the left anterior descending coronary artery, which was frozen at $-80^{\circ} \mathrm{C}$ for five minutes, and then sliced into $2 \mathrm{~mm}$ transverse sections and stained using 2,3,5-triphenyl tetrazolium chloride
$(1.5 \% \mathrm{TTC})$ and myocardial infarction size $(\times 2)$ was thus confirmed [21]).

\section{Tissue preparation}

The rest of the myocardium was washed using DEPC (diethylpyrocarbonate) $\mathrm{H}_{2} \mathrm{O}$. The anterior myocardial regional tissue sample (50 mg), which was non-colored tissue using Evan's blue was separated from the edge of the myocardial infarct risk area of the left ventricle. Tissue was frozen using liquid nitrogen and stored at $-80^{\circ} \mathrm{C}$ for future real time RT-PCR use; the remainder was put into $4 \%$ paraformaldehyde for $12 \mathrm{~h}$, paraffin embedded, and sectioned (thickness of $4 \mu \mathrm{m}$ ) for immunohistochemical staining.

The expression of $\mathrm{Bax}, \mathrm{Bcl}-2$ and caspase- 3 mRNA was detected by real time RT-PCR

Total RNA was extracted from the samples by the TRIZOL reagent (Shanghai ShengGong Biological Engineering

\section{A}

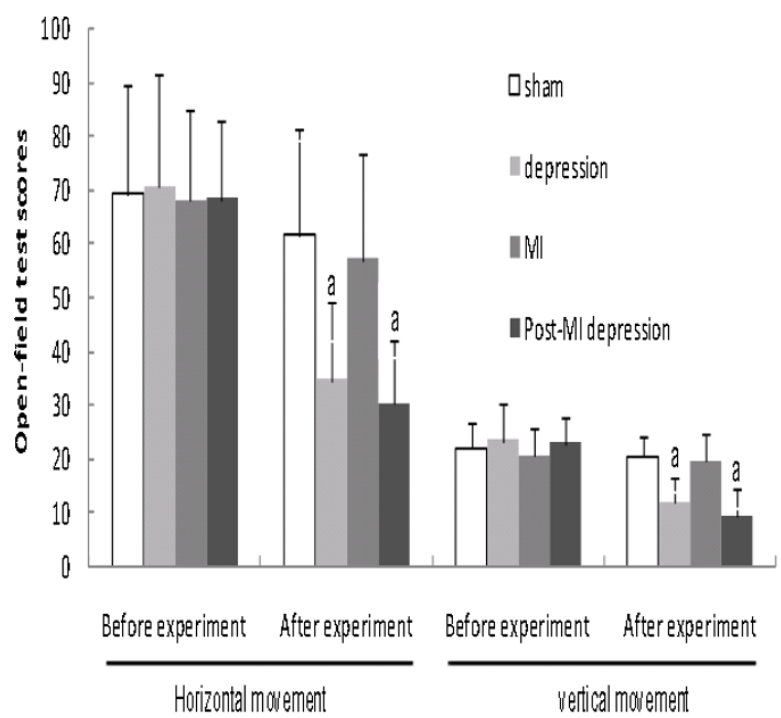

B

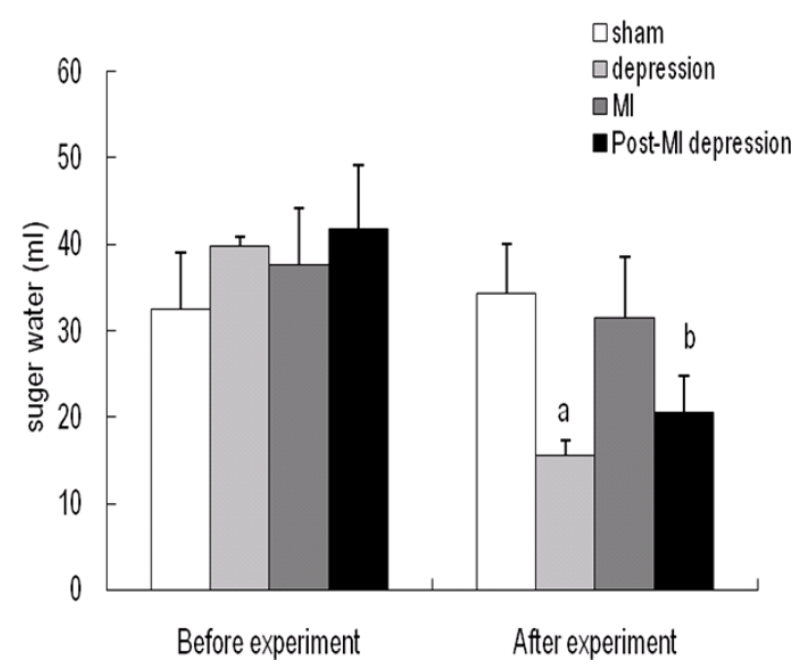

Figure 2 The behavioral changes in open-field and sucrose consumption test. Rats in both the depression and post-MI (myocardial infarction) depression groups showed significantly lower scores of both horizontal and vertical movement compared with the sham and Ml groups ( $\left.{ }^{a} P<0.01\right)(\mathbf{A})$. The total consumptions of sucrose was significantly lower in the depression and post-MI depression groups compared to the sham and $\mathrm{Ml}$ groups after the experiment ( $\left.{ }^{\mathrm{a}} \mathrm{P}<0.01,{ }^{\mathrm{b}} \mathrm{P}<0.05\right)(\mathbf{B})$. 
Services Co., LTD, Shanghai, China). Primers were synthesized (Shanghai ShengGong Biological Engineering Services Co., LTD, Shanghai, China). cDNA was synthesized (Invitrogen Corp., San Diego, California USA) by combining the components $\left(5 \times\right.$ VILO $^{\mathrm{TM}}$ Reaction Mix 4 $\mu \mathrm{l}, 10 \times$ Superscript Enzyme Mix $2 \mu \mathrm{l}$, RNA (up to $2.5 \mu \mathrm{g}$ ) $\mathrm{X} \mu \mathrm{l}$ and DEPC-treated water to $20 \mu \mathrm{l}$ ). Tube contents were gently mixed and incubated at $25^{\circ} \mathrm{C}$ for 10 minutes. Tubes were incubated at $42^{\circ} \mathrm{C}$ for 60 minutes. The reaction was terminated at $85^{\circ} \mathrm{C}$ at 5 minutes. cDNA was amplified with Power SYBR Green PCR Master Mix (Roche Molecular Biochemicals, Basel, Switzerland) for each gene, by the Applied Biosystems StepOne ${ }^{\mathrm{TM}}$ and Stepone Plus ${ }^{\mathrm{TM}}$ real-time PCR System (Foster City, California, USA): pre-denaturation $95^{\circ} \mathrm{C}$ for 10 minutes, denaturation $95^{\circ} \mathrm{C}$ for $15 \mathrm{~s}$, annealing $60^{\circ} \mathrm{C}$ for 1 minute, extending $72^{\circ} \mathrm{C}$ for 1 minute, denaturation and annealing for a total of 40 cycles, extending again $72^{\circ} \mathrm{C}$ for 10 minutes. PCR products were analyzed by quantitative high-resolution DNA melting analysis. $\beta$-actin was used as an internal standard. Table 2 shows Primer series of Bax, Bcl-2 and $\beta$-actin, caspase- 3 gene.

\section{Quantitative measure of $\mathrm{Bcl}-2$ and Bax protein by immunohistochemical staining}

For Bax and Bcl-2 protein determination [35], immunohistochemical staining kits for Bax, Bcl-2 were provided by Wuhan Boster Bioengineering Co., Ltd. (Wuhan, China). The sections (thickness of $4 \mu \mathrm{m}$ ) were de-waxed and rehydrated with freshly distilled water. At room temperature, samples underwent inactivation of endogenous peroxidase for 10 minutes and were washed with distilled water for 2 minutes (three times), then immersed in $0.1 \mathrm{~mol} / \mathrm{L}$ citrate buffer solution ( $\mathrm{pH}=6.0)$ and heated in a microwave oven until boiling (twice, with a 5-minute interval). After refrigerated flushing three times with phosphate buffered saline (PBS) for 2 minutes, antigen-retrieval buffers were added for 10 minutes and tissues were then flushed three times with PBS for 2 minutes. At room temperature, samples were non-specifically blocked with normal goat serum for 20 minutes. After removal of the goat serum, rabbit anti-Bax, Bcl-2 antibody was added (incubated for 60 minutes at $37^{\circ} \mathrm{C}$ ). Biotinylated goat anti-rabbit antibody immunoglobulin $\mathrm{G}$ was applied for 20 minutes and flushed with PBS for 2 minutes (three times), then the tissues were placed in a streptavidin-biotin-enzyme complex reagent, incubated for 20 minutes at $37^{\circ} \mathrm{C}$, after flushing with PBS for 5 minutes (four times), samples were stained with diaminobenzidine for 25 minutes and washed for 3 minutes. Then samples were stained with hematoxylin, and were dehydrated and mounted for microscopic examination. Images of the sections were obtained (400 X) using the Image-Pro Plus 4.5 software (Media Cybernetics, Silver. Spring, USA) with brown cytoplasmic staining under light microscopy indicating a positive reaction of Bax, Bcl2 . The myocardial infarction border zone was chosen using a 10 high power fields $(400 \times)$, in which the mean number of bax and bcl-2 positive cells were obtained. The Bax:Bcl-2 ratio was also confirmed.

\section{Statistical analysis}

The analyses were conducted using IBM SPSS 19.0 analysis software (SPSS Inc, Chicago, Illinois, USA). One-way ANOVA test was performed to examine the data among groups (mean \pm SEM) with the Bonferroni post-hoc tests for multiple comparisons. There was a significant difference $(P<0.05)$ and all the statistical tests were two-tailed.

\section{Results}

\section{Infarct size}

The myocardial infarct risk area of the left ventricular area was $65 \pm 2 \%$ (mean \pm SEM) indicated by Evan Blue staining. The myocardial infarct size in the myocardial infarct risk area was similar in both groups: (MI group $43.2 \pm 1.9 \%$; post-MI depression group $45.6 \pm 2.6 \%)$. No difference was seen between the MI and post-MI depression groups.

\section{The expression of $\mathrm{Bax}$ and $\mathrm{Bcl}-2$ mRNA and $\mathrm{Bax} / \mathrm{Bcl}-2$ ratio}

The ratio of Bax:Bcl-2 (mean \pm SEM) in the depression, MI and post-MI depression groups was statistically significantly larger than in the sham group $(P<0.05)$. The ratio of Bax-Bcl-2 was significantly larger in $\mathrm{MI}$ group than the depression group $(P<0.05)$, and this ratio was significantly greater in the post-MI depression group compared with the MI group $(P<0.05)$ (Table 3$)$.

\section{The expression of $\mathrm{Bax}$ and $\mathrm{Bcl}-2$ protein and $\mathrm{Bax} / \mathrm{Bcl}-2$ ratio}

There was a significantly higher ratio of Bax:Bcl-2 (mean \pm $\mathrm{SEM}$ ) in the myocardium in the depression, $\mathrm{MI}$ and postMI depression groups than in the sham group $(P<0.01)$. Furthermore, in the post-MI depression group there was a

Table 2 Primer series of Bax, Bcl-2, $\beta$-actin and caspase-3

\begin{tabular}{|c|c|c|c|}
\hline Genes & upstream $\left(5^{\prime}-3^{\prime}\right)$ & downstream $\left(5^{\prime}-3^{\prime}\right)$ & $\mathrm{Bp}$ \\
\hline Bax & GCGATGAACTGGACAACAACAT & TAGCAAAGTAGAAAAGGGCAACC & 153 \\
\hline $\mathrm{BCl}-2$ & ATGTGTGTGGAGAGCGTCAACC & CCAGGAGAAATCAAACAGAGGC & 174 \\
\hline$\beta$-actin & ATGGTGGGTATGGGTCAGAA & ACCCTCATAGATGGGCACAG & 375 \\
\hline caspase-3 & TGGTTCATCCAGTCGCTITGT & CAAATTCTGTTGCCACCTITCG & 103 \\
\hline
\end{tabular}


Table 3 The expression of caspase 3, Bax and Bcl-2 mRNA and Bax/Bcl-2 ratio (mean \pm SEM, copies/g RNA)

\begin{tabular}{cllll}
\hline Groups & Casp-3 mRNA & Bax mRNA & BcL-2 mRNA & Bax/bcl-2 \\
\hline Sham (8) & $0.66(0.34)$ & $2.85(0.58)$ & $0.88(0.19)$ & $3.29(0.67)$ \\
Depression (8) & $0.67(0.08)$ & $10.73(1.20)^{\mathrm{a}}$ & $1.97(0.26)^{\mathrm{a}}$ & $5.55(1.28)^{\mathrm{b}}$ \\
MI (13) & $0.92(0.55)$ & $23.23(1.97)^{\mathrm{a}, \mathrm{c}}$ & $3.12(0.10)^{\mathrm{a}, \mathrm{c}}$ & $7.47(0.86)^{\mathrm{a}, \mathrm{d}}$ \\
Post-MI Depression (7) & $0.95(0.42)$ & $46.79(2.75)^{\mathrm{a}, c_{\mathrm{c}}}$ & $5.08(0.55)^{\mathrm{a}} \mathrm{c}_{\mathrm{e}}$ & $9.26(0.67)^{\mathrm{a}, \mathrm{c}, \mathrm{f}}$ \\
$\boldsymbol{F}$ & 0.481 & 333.978 & 93.541 & 24.171 \\
$\boldsymbol{P}$ & 0.704 & 0.000 & 0.000 & 0.000 \\
\hline
\end{tabular}

The ratio of Bax:Bcl-2 (mean \pm SEM) in the depression, Ml (myocardial infarction) and post-Ml depression groups was significantly larger than in the sham group ( $\left.{ }^{\mathrm{a}} P<0.01,{ }^{\mathrm{b}} P<0.05\right)$, the $\mathrm{Ml}$ and post-MI depression group was significantly larger than the depression group ( $\left.{ }^{\mathrm{c}} P<0.01,{ }^{\mathrm{d}} P<0.05\right)$, and the post-MI depression group was a significantly greater than the Ml group $\left({ }^{\mathrm{e}} P<0.01,{ }^{\mathrm{f}} P<0.05\right)$.

significantly higher ratio of Bax:Bcl-2 than in the depression and MI groups $(P<0.01)$, and in the MI group there was a significantly higher ratio of $\mathrm{Bax}: \mathrm{Bcl}-2$ than in the depression group $(P<0.01)$ (Table 4$)$.

\section{Caspase-3 levels}

No difference was seen in caspase-3 levels among the sham, depression, MI and post-MI depression groups (Table 3).

\section{Discussion}

There is an established link between depression and myocardial infarction in morbidity; however, the mechanisms underpinning this association are not comprehensively elucidated [36]. In this study, we demonstrated the behavioral phenotype of depression after myocardial infarction, characterized by lower scores of horizontal movements, vertical movements and reduced consumption of sucrose solution, in the depression and post-MI depression rats. These are models of lowered emotional activity and exploratory behavior, where the post-MI depression group demonstrated altered reward preference.

Apoptosis is an ordered, active, non-inflammatory process of cell death caused by a pathological or physiological stimulation of a genetically mediated regulatory system. Previous studies have demonstrated that in ischemia and reperfusion damage, apoptosis in the myocardium plays a role in the pathology of heart diseases, including myocardial infarction and dilated cardiomyopathy $[21,37]$. Cardiomyocyte apoptosis is a key form of cell death, and apoptotic cell death plays an important role in the development of heart failure [38].
There are two major apoptotic pathways in mammalian cells, "intrinsic" and "extrinsic". Both kinds of apoptotic pathways were observed simultaneously in the experiment secondary to activation and non-activation of caspase-3, which may cause cleavage of substrates and cell death. The mitochondrial-mediated pathway of apoptosis is regulated by the $\mathrm{Bcl}-2$ family of antiapoptotic (Bcl-2, Bcl-xl, $\mathrm{Mcl}-1$ ) and proapoptotic proteins (Bax, Bad and Bak), and $\mathrm{Bcl}-2$ inhibits apoptosis by interacting and forming inactivating heterodimers with Bax/Bak. It has been suggested that the $\mathrm{Bax} / \mathrm{Bcl}-2$ ratio may be more important than either promoter alone in determining apoptosis. The Bax/ Bcl-2 ratio is a measure of a cell's vulnerability to apoptosis; therefore, in our study, the use of a more sensitive, $\mathrm{Bax} / \mathrm{Bcl}-2$ ratio predominantly reflected apoptosis. In myocytes, the "intrinsic" pathway is primarily activated when cells are stimulated by hypoxia, ischemia-reperfusion and oxidative stress [26]. Oxidative stress has been hypothesized in part to mediate the link between somatic and psychiatric disorders [39]. Cardiac dysfunction and heart failure are documented after acute emotional stress [40]. The pathway of apoptosis is influenced by the Bax/Bcl-2 ratio and activated caspase- 3 . A high $\mathrm{Bax} / \mathrm{Bcl}-2$ ratio is associated with greater vulnerability to apoptotic activation, while a high caspase-3 level is often associated with apoptotic activity.

We observed that there was an increased myocardial Bax:Bcl-2 ratio in the depression, MI and post-MI depression groups, this was particularly so in the latter group, where there was a greater Bax:Bcl-2 ratio which is important in determining a cell's vulnerability to apoptosis. $\mathrm{Up}$-regulation of the $\mathrm{Bax} / \mathrm{Bcl}-2$ ratio can induce greater

Table 4 The expression of Bax and $\mathrm{Bcl}-2$ protein and Bax/Bcl-2 ratio (mean \pm SEM, IOD)

\begin{tabular}{llll}
\hline Groups $(\mathbf{n})$ & Bax & Bcl-2 & Bax/Bcl-2 \\
\hline Sham (8) & $3.32(0.92)$ & $2.74(1.03)$ & $1.14(0.22)$ \\
Depression (8) & $9.47(2.5)^{\mathrm{a}}$ & $6.18(2.21)^{\mathrm{a}}$ & $1.55(0.30)^{\mathrm{a}}$ \\
MI (13) & $27.63(5.61)^{\mathrm{a}, \mathrm{b}}$ & $9.42(3.75)^{\mathrm{a}}$ & $2.83(0.51)^{\mathrm{a}, \mathrm{b}}$ \\
Post-Ml depression (7) & $53.88(16.18)^{\mathrm{a}, \mathrm{b}, \mathrm{c}}$ & $14.82(3.71)^{\mathrm{a}, \mathrm{c}}$ & $3.77(0.64)^{\mathrm{a}, \mathrm{b}, \mathrm{c}}$ \\
\hline
\end{tabular}

There was a significantly higher ratio of Bax:Bcl-2 (mean \pm SEM) in the myocardium in the depression, MI (myocardial infarction) and post-MI depression groups than in the sham group $\left({ }^{\mathrm{a}} \mathrm{P}<0.01\right)$. Furthermore, in the post-MI depression and $\mathrm{Ml}$ groups there was a significantly higher ratio of Bax:Bcl-2 than in the depression group $\left({ }^{\mathrm{b}} P<0.01\right)$, and in the post-Ml group there was a significantly higher ratio of $\mathrm{Bax}: \mathrm{Bcl}-2$ than in the $\mathrm{Ml}$ group ( $\left.{ }^{\mathrm{C}} P<0.01\right)$. 
apoptotic activity [16,17], suggesting that there was greater vulnerability to apoptosis of myocardial cells with acute myocardial infarction with comorbid major depression. These data suggest that post-MI depression can activate pro-apopotic pathways; however, the regulatory mechanisms underlying apoptosis in the myocardium remain unclear.

This study also demonstrated that the up-regulated $\mathrm{Bax} / \mathrm{Bcl}-2$ ratio may modulate apoptosis associated with progression of the disease [41]. The $\mathrm{Bax} / \mathrm{Bcl}-2$ ratio may serve as an independent predictive marker of the therapeutic response [42], and merits further examination, as the myocardial infarction with depression induced increase of the $\mathrm{Bax} / \mathrm{Bcl}-2$ ratio might enhance apoptosis of cardiomyocyte $[43,44]$. These data suggest that depression after myocardial infarction may increase the $\mathrm{Bax} / \mathrm{Bcl}-2$ ratio and induce further cardiomyocyte apoptosis, which may play an important role in the higher morbidity after myocardial infarction in conjunction with depression.

Contrary to hypotheses, we found no difference in caspase-3 in the myocardium of the post-MI depression group versus the MI, depression and sham groups. This may indicate that caspase- 3 is not an active pathway to apoptosis in the myocardium in the model of myocardial infarction with depression. In interpreting this, several factors should be considered. First, caspase- 3 may not be activated during the post-MI depression. It is possible that caspase- 3 activity was low because the apoptotic process in the myocardium was only finished two weeks post-MI. Second, it is possible that caspase-3 activity may induce apoptosis via another independent pathway. Third, the up-regulated $\mathrm{Bax} / \mathrm{Bcl}-2$ ratio may decrease the cell's viability in involving other effector caspases without the activity of caspase-3 [16]. Other caspases may be involved. Lancel et al. [45] showed that endotoxin induced increases in ventricular cardiomyocyte caspase$3,-8$ and -9 -like activities. This was associated with sarcomeric structure damage and cleavage of components of the cardiac myofilament. Frantz et al. [46] noted that rats with deletion of the caspase-1 gene showed increased peri-infarct survival and a lower rate of ventricular dilatation and a decreased rate of apoptosis after a model of myocardial infarction.

However, we did not find a relationship between other caspases and the model of MI with depression. Apoptotic pathways may interact with other pathways of shared risk including ischemia and reperfusion damage, inflammatory and oxidative pathways $[38,47,48]$ and other nonspecific mechanisms, suggesting the need for further exploration of these interactions.

In this study, we found a depressive-analog anhedonialike state in rats after myocardial infarction. These changes have parallels with the core symptoms of depression.
There may be a mechanistic association with the up-regulation of the $\mathrm{Bax} / \mathrm{Bcl}-2$ ratio in the myocardium after myocardial infarction with depression. Our study demonstrated that in rats with post-MI depression, there is an increase in pro-apoptotic pathways in myocardium after myocardial infarction. Cardiomyocyte apoptosis is a key form of cell death, and apoptotic cell death plays an important role in the development of heart failure [38], resulting in a decreased heart function and reduced cardiac output.

There are certain limitations that need to be kept in mind when interpreting these data. First, our previous study demonstrated that in rats with chronic mild stress, there is an increase in pro-apoptotic pathways in the myocardium and hippocampus after depression, which was reversed by venlafaxine. To extend this line of study, our purpose was to attempt to evaluate myocardial apoptosis after myocardial infarction with depression, to clarify the molecular mechanisms, as well as confirm whether the higher incidence of myocardial infarction with depression is associated with apoptosis pathways, so the use of an inhibitor of apoptosis after myocardial infarction may further clarify the role of apoptosis. Similarly, the use of a chronic unpredictable stress-depressed (depression) group on which surgery is performed as another "control" group could have assisted interpretation of these results. Second, in our experiment, only 7 out of 20 myocardial infarction rats developed an anhedonic-like state compared to sham and depression groups; this pattern differs from reports by other groups and may be related to methodological variance. Third, it would also have been helpful for the sucrose test to have been done weekly in addition to baseline and endpoint readings. Further experimentation will clarify this point. In addition, although our results showed no effect of caspase-3 level in the myocardium after myocardial infarction and depression, it may induce apoptosis via an independent caspase-3 pathway, or other caspases expressed in the heart, suggesting again the need for further study.

\section{Conclusions}

The results of this animal model suggest that active proapoptotic pathways may be involved in the nexus between cardiovascular disorders and depression. The operative mechanism might be the effects of apoptosis vulnerability markers on the myocardium in the model of depression after myocardial infarction. Apoptotic pathways may interact with other pathways of shared risk including ischemia and reperfusion damage, inflammatory and oxidative pathways, and other non-specific mechanisms. These data nevertheless suggest that active pro-apoptotic pathways may be involved in the morbidity after myocardial infarction in those with MDD. This mechanism may be germane to understanding this relationship in humans. 
A clear understanding of these pathways could shed light on the potential protective effects from further heart damage after myocardial infarction with depression, as well as their effects on common pathways to medical comorbidity.

\section{Abbreviations}

APA: American Psychological Association; CAD: coronary artery disease; CMS: chronic mild stress; DEPC: diethypyrocarbonate; ECG: electrocardiogram; MDD: major depressive disorder; MI: myocardial infarction; $\mathrm{NIH}$ : National Institute of Health; PBS: phosphate buffered saline; RT-PCR: reverse transcription - polymerase chain reaction; SNRI: serotonin-norepinephrine reuptake inhibitor; TTC: 2,3,5-triphenyl tetrazolium chloride

\section{Authors' contributions}

YW conceived of the study. XL participated in the design of the study and performed the statistical analysis. MB and YW participated in the sequence alignment and drafted the manuscript. MB critically revised the manuscript for important intellectual content. DZ, JC and SL carried out behavioral tests, molecular genetic studies and immunohistochemistry tests. All authors participated in data interpretation, drafting of the manuscript and have read and approved the final manuscript.

\section{Competing interests}

MB has received Grant/Research Support from the $\mathrm{NIH}$, Cooperative Research Centre, Simons Autism Foundation, Cancer Council of Victoria, Stanley Medical Research Foundation, MBF, NHMRC, Beyond Blue, Geelong Medical Research Foundation, Bristol Myers Squibb, Eli Lilly, Glaxo SmithKline, Organon, Novartis, Mayne Pharma and Servier; and has been a speaker for Astra Zeneca, Bristol Myers Squibb, Eli Lilly, Glaxo SmithKline, Janssen Cilag, Lundbeck, Merck, Pfizer, Sanofi Synthelabo, Servier, Solvayand Wyeth; and served as a consultant to Astra Zeneca, Bristol Myers Squibb, Eli Lilly, Glaxo SmithKline, Janssen Cilag, Lundbeck and Servier. The other authors declare that they have no conflicts of interest.

\section{Acknowledgements}

The authors would like to thank Dr. JM Hodge (Barwon Biomedical Research, The Geelong Hospital, Geelong, Victoria 3220, Australia) for figure preparation. This study was supported and financed for Yiming Wang et al. by the Science and Technology Fund of Guizhou Province (China), Qian subjects in T (2006) 2065, SY (2008) 3063; it was supported by Scientific and Technology Projects in Guiyang City (China), Zhu subjects agriculture in Contract 3-008, and High-Level Personnel Research Conditions, Special Assistant Funding (TZJF-2008 55), National Natural Science Foundation of China, Project Grant: 31260237 for study design, the collection, analysis, and interpretation of data and the writing of the manuscript.

\section{Author details}

'Department of Psychiatry, Hospital Affiliated to Guiyang Medical University, 28 Guiyi Street, Guiyang City, 550004, Guizhou, China. ${ }^{2}$ School of Medicine, Deakin University, 1 Gheringhap Street, Geelong, VIC 3220, Australia. ${ }^{3}$ Department of Cardiology, Hospital Affiliated to Guiyang Medical University, 28 Guiyi Street, Guiyang City, 550004, Guizhou, China. ${ }^{4}$ Department of Neurology, The General Hospital of Hebi Coal Corp, 84 Honggi Street, Hebi City, 458000, Henan, China. ${ }^{5}$ Department of Psychiatry, The University of Melbourne, Level 1, North Block Main, Building Royal Melbourne Hospital, Parkville, VIC 3050, Australia. ${ }^{6}$ Orygen Youth Health Research Centre, Centre for Youth Mental Health, 35 Poplar, Road, Parkville VIC 3052, Australia. ${ }^{7}$ Florey Institute of Neuroscience and Mental Health, Level 3, Alan Gilbert Building, 161 Barry Street, University of Melbourne, Parkville, VIC 3010, Australia.

Received: 8 May 2012 Accepted: 8 February 2013

Published: 8 February 2013

\section{References}

1. Charlson FJ, Stapelberg NJ, Baxter AJ, Whiteford HA: Should global burden of disease estimates include depression as a risk factor for coronary heart disease? BMC Med 2011, 9:1-6.
2. Ikenouchi-Sugita A, Yoshimura R, Kishi T, Umene-Nakano W, Hori H, Hayashi K, Katsuki A, Ueda N, Iwata N, Nakamura J: Three polymorphisms of the eNOS gene and plasma levels of metabolites of nitric oxide in depressed Japanese patients: a preliminary report. Hum Psychopharmacol 2011, 26:531-534.

3. May HT, Horne BD, Carlquist JF, Sheng X, Joy E, Catinella AP: Depression after coronary artery disease is associated with heart failure. J Am Coll Cardiol 2009, 53:1440-1447.

4. Spertus JA, McDonell M, Woodman CL, Fihn SD: Association between depression and worse disease-specific functional status in outpatients with coronary artery disease. Am Heart J 2000, 140:105-110.

5. Pignay-Demaria V, Lespérance F, Demaria FG, Frasure-Smith N, Perrault LP: Depression and anxiety and outcomes of coronary artery bypass surgery. Ann Thorac Surg 2003, 75:314-321.

6. Thom T, Haase N, Rosamond W, Howard VJ, Rumsfeld J, Manolio T, Zheng ZJ, Flegal K, O'Donnell C, Kittner S, Lloyd-Jones D, Goff DC Jr, Hong Y, Adams R, Friday G, Furie K, Gorelick P, Kissela B, Marler J, Meigs J, Roger V, Sidney S, Sorlie P, Steinberger J, Wasserthiel-Smoller S, Wilson M, Wolf P: Heart disease and stroke statistics-2006 update: a report from the American Heart Association Statistics Committee and Stroke Statistics Subcommittee. Circulation 2006, 113:e85-151.

7. Strik JJ, Honig A, Maes M: Depression and myocardial infarction: relationship between heart and mind. Prog Neuropsychopharmacol Biol Psychiatry 2001, 25:879-892.

8. von Känel R, Begré S: Depression after myocardial infarction: unraveling the mystery of poor cardiovascular prognosis and role of beta-blocker therapy. J Am Coll Cardiol 2006, 48:2215-2217.

9. van Melle JP, de Jonge P, Spijkerman TA, Tijssen JG, Ormel J, van Veldhuisen DJ, van den Brink RH, van den Berg MP: Prognostic association of depression following myocardial infarction with mortality and cardiovascular events: a meta-analysis. Psychosom Med 2004, 66:814-822.

10. Carney RM, Freedland KE: Depression, mortality, and medical morbidity in patients with coronary heart disease. Biol Psychiatry 2003, 54:241-247.

11. Fauerbach JA, Bush DE, Thombs BD, McCann UD, Fogel J, Ziegelstein RC: Depression following acute myocardial infarction: a prospective relationship with ongoing health and function. Psychosomatics 2005, 46:355-361.

12. Nuñez G, Clarke MF: The Bcl-2 family of proteins: regulators of cell death and survival. Trends Cell Biol 1994, 4:399-403.

13. White E: Life, death and the pursuit of apoptosis. Genes Dev 1996, 10:1-15.

14. Vekrellis K, McCarthy MJ, Watson A, Whitfield J, Rubin LL, Ham J: Bax promotes neuronal cell death and is downregulated during the development of the nervous system. Development 1997, 124:1239-1249.

15. Cory S, Huang DC, Adams JM: The BCl-2 family: roles in cell survival and oncogenesis. Oncogene 2003, 22:8590-8607.

16. Jarskog LF, Selinger ES, Lieberman JA, Gilmore JH: Apoptotic proteins in the temporal cortex in schizophrenia: high bax/bcl-2 ratio without caspase-3 activation. Am J Psychiatry 2004, 161:109-115.

17. Oltvai $\mathrm{ZN}$, Milliman $\mathrm{CL}$, Korsmeyer $\mathrm{SJ}$ : $\mathrm{BCl}-2$ heterodimerizes in vivo with a conserved homolog, Bax, that accelerates programmed cell death. Cell 1993, 74:609-619.

18. Wann BP, Bah TM, Kaloustian S, Boucher M, Dufort AM, Le Marec N, Godbout R, Rousseau G: Behavioural signs of depression and apoptosis in the limbic system following myocardial infarction: effects of sertraline. J Psychopharmacol 2009, 23:451-459.

19. Fan TJ, Han LH, Cong RS, Liang J: Caspase family proteases and apoptosis. Acta Biochim Biophys Sin 2005, 37:719-727.

20. Boucher M, Wann BP, Kaloustian S, Massé R, Schampaert E, Cardinal R, Rousseau G: Sustained cardioprotection afforded by A2A adenosine receptor stimulation after 72 hours of myocardial reperfusion. J Cardiovasc Pharmacol 2005, 45:439-446.

21. Wann BP, Boucher M, Kaloustian S, Nim S, Godbout R, Rousseau G: Apoptosis detected in the amygdala following myocardial infarction in the rat. Biol Psychiatry 2006, 59:430-433.

22. Girard SA, Bah TM, Kaloustian S, Lada-Moldovan L, Rondeau I, Tompkins TA, Godbout R, Rousseau G: Lactobacillus helveticus and Bifidobacterium longum taken in combination reduce the apoptosis propensity in the limbic system after myocardial infarction in a rat model. Br J Nutr 2009, 102:1420-1425

23. Wann BP, Bah TM, Boucher M, Courtemanche J, Le Marec N, Rousseau G, Godbout R: Vulnerability for apoptosis in the limbic system after 
myocardial infarction in rats: a possible model for human postinfarct major depression. J Psychiatry Neurosci 2007, 32:11-16.

24. Wang $Y$, Xiao Z, Liu X, Berk M: Venlafaxine modulates depression-induced behaviour and the expression of Bax mRNA and Bcl-xl mRNA in both hippocampus and myocardium. Hum Psychopharmacol 2011, 26:95-101.

25. Willner P, Muscat R, Papp M: Chronic mild stress-induced anhedonia: a realistic animal model of depression. Neurosci Biobehav Rev 1992. 16:525-534.

26. Wu JC, Chen IY, Wang Y, Tseng JR, Chhabra A, Salek M, Min JJ, Fishbein MC, Crystal R, Gambhir SS: Molecular imaging of the kinetics of vascular endothelial growth factor gene expression in ischemic myocardium. Circulation 2004, 110:685-691.

27. Wehrens XH, Kirchhoff S, Doevendans PA: Mouse electrocardiography: an interval of thirty years. Cardiovasc Res 2000, 45:231-237.

28. Moreau JL, Jenck F, Martin JR, Mortas P, Haefely WE: Antidepressant treatment prevents chronic unpredictable mild stress-induced anhedonia as assessed by ventral tegmentum self-stimulation behavio in rats. Eur Neuropsychopharmacol 1992, 2:43-49.

29. Willner P, Towell A, Sampson D, Sophokleous S, Muscat R: Reduction of sucrose preference by chronic unpredictable mild stress, and its restoration by a tricyclic antidepressant. Psychopharmacology 1987, 93:358-364.

30. Montgomery KS, Mackey J, Thuett K, Ginestra S, Bizon JL, Abbott LC Chronic, low-dose prenatal exposure to methylmercury impairs motor and mnemonic function in adult C57/B6 mice. Behav Brain Res 2008, 191:55-61.

31. Grippo AJ, Beltz TG, Weiss RM, Johnson AK: The effects of chronic fluoxetine treatment on chronic mild stress-induced cardiovascular changes and anhedonia. Biol Psychiatry 2006, 59:309-316

32. Katz RJ, Roth KA, Carroll BJ: Acute and chronic stress effects on open field activity in the rat: implications for a model of depression. Neurosci Biobehav Rev 1981, 5:247-251.

33. Erdodan F, Golgeli A, Arman F, Ersoy AO: The effects of pentylenetetrazole induced status epilepticus on behavior, emotional memory and learning in rats. Epilepsy Behav 2004, 5:388-393.

34. Henningsen $\mathrm{K}$, Andreasen JT, Bouzinova EV, Jayatissa MN, Jensen MS, Redrobe JP, Wiborg O: Cognitive deficits in the rat chronic mild stress model for depression: relation to anhedonic-like responses. Behav Brain Res 2009, 198:136-141.

35. Zhang H, Liu L, Huang G, Zhou L, Wu W, Zhang T, Huang H: Protective effect of electroacupuncture at the Neiguan point in a rabbit model of myocardial ischemia-reperfusion injury. Can J Cardiol 2009, 25:359-563.

36. McConnell S, Jacka FN, Williams $\sqcup$, Dodd S, Berk M: The relationship between depression and cardiovascular disease. Int J Psychiatry Clin Pract 2005, 9:157-167.

37. Ho YL, Chen CL, Hsu RB, Lin LC, Huang PJ: The correlation between expression of apoptosis-related proteins and myocardial functional reserve evaluated by dobutamine stress echocardiography in patients with dilated cardiomyopathy. J Am Soc Echocardiogr 2003, 16:931-936.

38. van Empel VP, Bertrand AT, Hofstra L, Crijns HJ, Doevendans PA, De Windt LJ: Myocyte apoptosis in heart failure. Cardiovasc Res 2005, 67:21-29.

39. Pasco JA, Nicholson GC, Ng F, Henry MJ, Williams LJ, Kotowicz MA, Hodge JM, Dodd S, Kaczynski F, Gama CS, Berk M: Oxidative stress may be a common mechanism linking major depression and osteoporosis. Acta Neuropsychiatrica 2008, 20:112-116.

40. Kurisu S, Sato H, Kawagoe T, Ishihara M, Shimatani Y, Nishioka K, Kono Y Umemura T, Nakamura S: Tako-tsubo-like left ventricular dysfunction with ST-segment elevation: a novel cardiac syndrome mimicking acute myocardial infarction. Am Heart J 2002, 143:448-455.

41. Moylan S, Maes M, Wray NR, Berk M: The neuroprogressive nature of major depressive disorder: pathways to disease evolution and resistance, and therapeutic implications. Mol Psychiatry 2012.

42. Salakou S, Kardamakis D, Tsamandas AC, Zolota V, Apostolakis E, Tzelepi V, Papathanasopoulos P, Bonikos DS, Papapetropoulos T, Petsas T, Dougenis D: Increased $\mathrm{Bax} / \mathrm{BCl}-2$ ratio up-regulates caspase-3 and increases apoptosis in the thymus of patients with myasthenia gravis. In Vivo 2007, 21:123-132.

43. Leri A, Claudio PP, Li Q, Wang X, Reiss K, Wang S, Malhotra A, Kajstura J, Anversa P: Stretch-mediated release of angiotensin II induces myocyte apoptosis by activating $p 53$ that enhances the local renin-angiotensin system and decreases the Bcl-2-to-Bax protein ratio in the cell. $J$ Clin Invest 1998, 101:1326-1342

44. Wernig F, Xu Q: Mechanical stress-induced apoptosis in the cardiovascular system. Prog Biophys Mol Biol 2002, 78:105-137.

45. Lancel S, Joulin O, Favory R, Goossens JF, Kluza J, Chopin C, Formstecher P, Marchetti $P$, Neviere R: Ventricular myocyte caspases are directly responsible for endotoxin-induced cardiac dysfunction. Circulation 2005, 111:2596-2604

46. Frantz S, Ducharme A, Sawyer D, Rohde LE, Kobzik L, Fukazawa R, Tracey D, Allen H, Lee RT, Kelly RA: Targeted deletion of caspase-1 reduces early mortality and left ventricular dilatation following myocardial infarction. J Mol Cell Cardiol 2003, 35:685-694

47. Pasco JA, Kotowicz MA, Henry MJ, Nicholson GC, Spilsbury HJ, Box JD, Schneider HG: High-sensitivity C-reactive protein and fracture risk in elderly women. JAMA 2006, 296:1353-1355.

48. Maes M, Ruckoanich P, Chang YS, Mahanonda N, Berk M: Multiple aberrations in shared inflammatory and oxidative \& nitrosative stress (IO\&NS) pathways explain the co-association of depression and cardiovascular disorder (CVD), and the increased risk for CVD and due mortality in depressed patients. Prog Neuropsychophrmacol Biol Psychiatry 2011, 35:769-783.

\section{Pre-publication history}

The pre-publication history for this paper can be accessed here: http://www.biomedcentral.com/1741-7015/11/32/prepub

doi:10.1186/1741-7015-11-32

Cite this article as: Wang et al:: The effects of apoptosis vulnerability markers on the myocardium in depression after myocardial infarction. BMC Medicine 2013 11:32.

\section{Submit your next manuscript to BioMed Central and take full advantage of:}

- Convenient online submission

- Thorough peer review

- No space constraints or color figure charges

- Immediate publication on acceptance

- Inclusion in PubMed, CAS, Scopus and Google Scholar

- Research which is freely available for redistribution
C Biomed Central 